\title{
CORROSION RESISTANCE OF Cissus quadrangularis EXTRACTS ON METAL IN AGGRESSIVE MEDIUM: GRAVIMETRIC AND SURFACE EXAMINATIONS
}

\author{
R. Anitha ${ }^{1}$ and Subramanian Chitra, ${ }^{2, *}$ \\ ${ }^{1}$ Department of Chemistry, SNS College of Technology, Coimbatore- 641035, Tamilnadu, India \\ ${ }^{2}$ Department of Chemistry, PSGR Krishnammal College for Women, \\ Coimbatore - 641004, Tamilnadu, India \\ *E-mail: rajshree1995@ rediffmail.com
}

\begin{abstract}
The corrosion resistance of Cissus quadrangularis in acid and ethanol medium have been investigated by diverse techniques. It has been noticed that as the concentration ( 2 to $12 \mathrm{v} / \mathrm{v} \%$ ) of $C$. quadrangularis rises the efficiency of the inhibitor also increases. The maximum inhibition efficiencies of $89.45 \%$ and $75.54 \%$ were attained for acid and ethanol extracts respectively. The emergence of a protective layer on the mild steel surface was assessed by electrochemical impedance studies. The influence of the active ingredients in the extracts was examined by GC-MS analysis. The inhibitor adsorption ensued in the protective layer on the surface was analyzed using SEM and AFM.

Keywords: $C$. quadrangularis, $G C$ - $M S$, Electrochemical Techniques, Adsorption Isotherm, SEM, AFM
\end{abstract}

CRASĀYAN. All rights reserved

\section{INTRODUCTION}

Mild steel is the dominant metal that has wide application in industries. It is highly affected due to corrosion because of the usage of acid solutions in industries for descaling, acid pickling, petrochemical processes etc. ${ }^{1,2}$ The metal corrosion in the corrosive medium is a complex problem world wide. To alleviate corrosion various proactive techniques such as improvement in materials, anodic/cathodic protection, coatings, modification of materials and corrosion inhibitors are used ${ }^{3,4}$. Among these techniques, corrosion inhibitors play a predominant role in protecting the metal against corrosion, particularly in acid medium. An organic compound functions as an inhibitor having hetero atoms, aromatic rings, conjugated double (or) triple bond, $\pi$-electrons in their structure ${ }^{5}$. In general, synthetic inhibitors are effective to abate corrosion but due to adverse effects of these inhibitors researchers are focussing towards non-toxic, cheap, biodegradable, readily existing green inhibitors ${ }^{6}$. A wide number of scientific research have been carried out to analyze the anti-corrosive property of various plant extracts on corrosion of metals, to discuss a few, Cymbopogan Citratus $^{7}$, Phyllanthus amarus ${ }^{8}$, Cascabela Thevetia ${ }^{9}$, Grewa Venusta ${ }^{10}$, Arecanut husk ${ }^{11}$. In our current research, we focussed on the easily available plant Cissus quadrangularis $(C Q)$. This plant originates under the type of vitaceae family with more traditional medicinal values. It is also termed as veld grape. CQ belongs to Srilanka and it is broadly spread in South East Asia, Arabic countries and Africa ${ }^{12}$. It possesses activities like gastro protective, anti-inflammatory anti-microbial, anti-tumor, etc. The literature evidenced the presence of amyrines, phenols, tannins etc., in CQ.

\section{Preparation of Inhibitor and Metal Specimen}

\section{EXPERIMENTAL}

Cissus quadrangularis were collected in the nearby vegetable market, washed thoroughly with water to eradicate impurities, dried. After the completion of drying it was powdered to obtain fine particles. About $1 \mathrm{~g}$ of the grounded sample was heated in $100 \mathrm{ml}$ of $0.5 \mathrm{M} \mathrm{H}_{2} \mathrm{SO}_{4}$ (acid extract) / $100 \mathrm{ml}$ of ethanol (ethanol extract) in a round-bottomed flask for 3 hours. The resultant green extracts [acid (CQAE)] and [ethanol (CQEE)] extracts were cooled at room temperature and filtered using Whatman filter paper.

Rasayan J. Chem., 12(3), 1326-1339(2019)

http://dx.doi.org/10.31788/RJC.2019.1235195

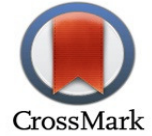


These extracts were stored in a refrigerator and utilized as an inhibitor for further analysis. Specimens were cut into rectangular sheets of specific dimensions $3 \mathrm{~cm} \times 1 \mathrm{~cm} \times 0.1 \mathrm{~cm}$ polished using emery paper, wiped with acetone and plates were kept in a moisture-free desiccator.

\section{Spectral Analysis}

\section{FT-IR Spectroscopy and GC-MS Analysis}

The active functional group existing in CQAE and CQEE extracts were recorded by Shimadzu IR affinity instruments. The bio phyto constituents present in the extracts were examined by Perkin Elmer Clasus 60 GC-MS instrument.

\section{Gravimetric Measurements}

After completion of pre cleaning process of metal coupons, the initial weight of the coupon was taken, suspended in a solution containing blank (un inhibited solution) and inhibited solutions (CQAE and CQEE) of concentrations $(2,4,6,8,10,12,14 \mathrm{v} / \mathrm{v} \%)$ in a $100 \mathrm{ml}$ beaker. After a specified time of 3 hours, the mild steel specimens were taken out, cleansed with water, dehydrated using warm air and reweighed. The loss in weight was calculated from the preliminary and final weights of the metal specimen. Differences in weight were used to evaluate inhibition efficiency (IE \%) and corrosion rate (CR) based on the formula ${ }^{13}$,

$$
\begin{gathered}
\text { Inhibition efficiency }(\% \text { IE })=\frac{\mathrm{W}_{\mathrm{bl}}-\mathrm{W}_{\text {in }}}{\mathrm{W}_{\mathrm{bl}} \times 100} \\
\text { Corrosion rate }\left(\mathrm{C}_{\text {rate }}\right)=\frac{534 \times \text { loss in weight } \quad(\mathrm{g})}{\text { Density }\left(\mathrm{g} / \mathrm{cm}^{3}\right) \times \text { Area }(\mathrm{cm}) \times \text { Time }(\mathrm{hr})}
\end{gathered}
$$

Where, $\mathrm{W}_{\mathrm{bl}}$ - blank weight loss, $\mathrm{W}_{\mathrm{in}}$ - inhibitor weight loss. The above-mentioned procedure was followed to scrutinize the impact of temperature on corrosion behavior. Gravimetric measurements were done in the range of temperature $(313-333 \mathrm{~K})$ and various parameters such as enthalpy and entropy, activation energy $\left(\mathrm{E}_{\mathrm{a}}\right)$, were determined by using the formula as reported in the previous literature ${ }^{14}$.

\section{Electrochemical Techniques}

The measurements based on electrochemical techniques such as impedance and polarisation studies for inhibited and uninhibited solutions were recorded using IVIUM compact stat Potentiostat/ Galvanostat. A traditional three-electrode cell assembly was utilized with the auxiliary electrode as platinum foil, saturated calomel electrode as reference and working electrode (mild steel specimen). Charge transfer resistance $\left(R_{\mathrm{ct}}\right)$ and double-layer capacitance $\left(\mathrm{C}_{\mathrm{dl}}\right)$ from the impedance graphs were determined ${ }^{15,16}$. Polarisation measurement was conducted in the range of $-200 \mathrm{mV}$ to $+200 \mathrm{mV}$ to get a smooth polarisation curve and scan rate was fixed to $1 \mathrm{mV} / \mathrm{sec}$. From this data $\mathrm{I}_{\text {corr }}$ (corrosion current), $\mathrm{E}_{\text {corr }}$ (corrosion potential) and Tafel slopes $\left(b_{a}\right.$ and $b_{c}$ ) were determined with and without the addition of the inhibitors. The inhibition efficacy was calculated using equation ${ }^{17}$,

$$
\begin{gathered}
\text { Inhibition efficiency }(\% \mathrm{IE})=\frac{\mathrm{R}_{\mathrm{ct}(\mathrm{in})}-\mathrm{R}_{\mathrm{ct}(\mathrm{bl})}}{\mathrm{R}_{\mathrm{ct}(\mathrm{in})}} \times 100 \\
\text { Inhibition efficiency }(\% \mathrm{IE})=\frac{\mathrm{I}_{\text {corr(bl) }}-\mathrm{I}_{\mathrm{corr}(\mathrm{in})}}{\mathrm{I}_{\mathrm{corr}(\mathrm{bl})}} \times 100
\end{gathered}
$$

\section{Surface Morphological Studies}

\section{Scanning Electron Microscope}

The metal coupons were suspended in the uninhibited and inhibited solution for 3 hours. Then they were detached from the beaker, cleansed with water, dried and analyzed using biomedical research microscope (Mumbai, India).

\section{Atomic Force Microscopy}

A multimode scanning probe microscope (NTMDT, NTEGRA prima, Russia) was utilized to examine the morphological analysis on the surface of the metal samples immersed in a solution containing inhibitor and without inhibitor for a specified time of 3 hours. Then it was taken out, washed, dried and analyzed. 


\section{FT-IR Spectra}

\section{RESULTS AND DISCUSSION}

CQAE and CQEE FT-IR spectra was portrayed in Fig.-1. Band at $3621 \mathrm{~cm}^{-1}, 1738 \mathrm{~cm}^{-1}, 1364 \mathrm{~cm}^{-1}$ correspond to $>\mathrm{OH},>\mathrm{C}=\mathrm{O},>\mathrm{CH}$ vibrations in CQAE. The absorption bands of CQEE at $3700 \mathrm{~cm}^{-1}, 1715$ $\mathrm{cm}^{-1}, 1410 \mathrm{~cm}^{-1}$ and $715 \mathrm{~cm}^{-1}$ are related to $>\mathrm{OH},>\mathrm{C}=\mathrm{O},>\mathrm{C}=\mathrm{C},>\mathrm{C}-\mathrm{H}$ vibrations.

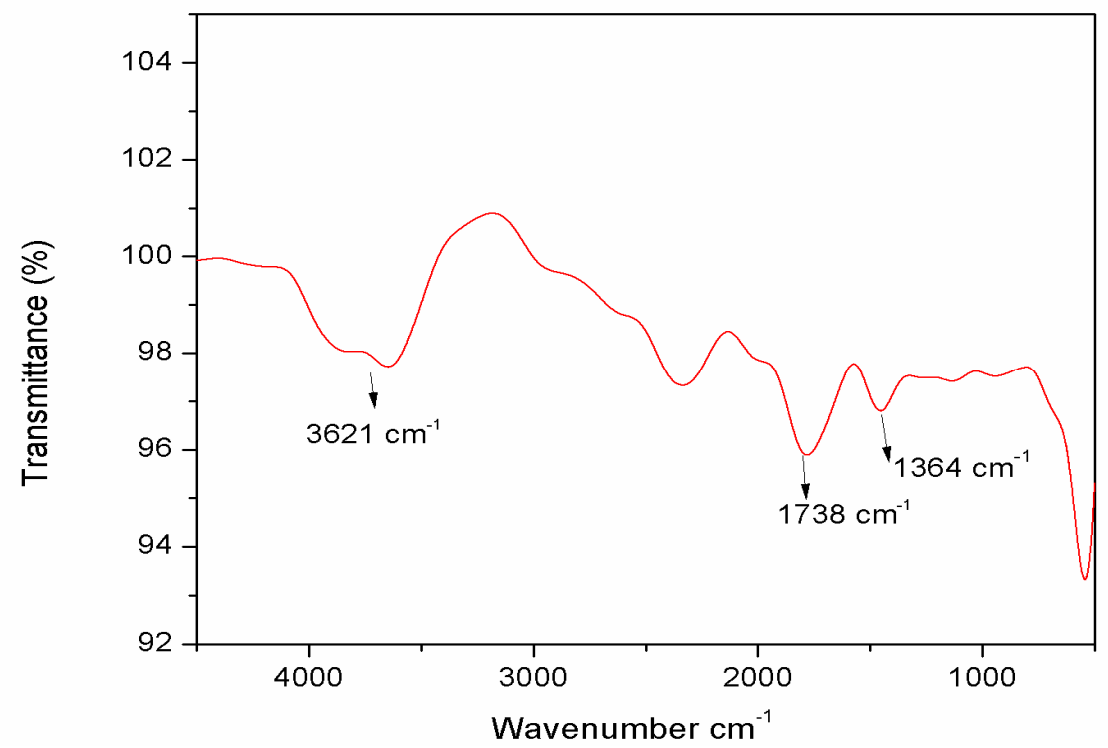

(a)

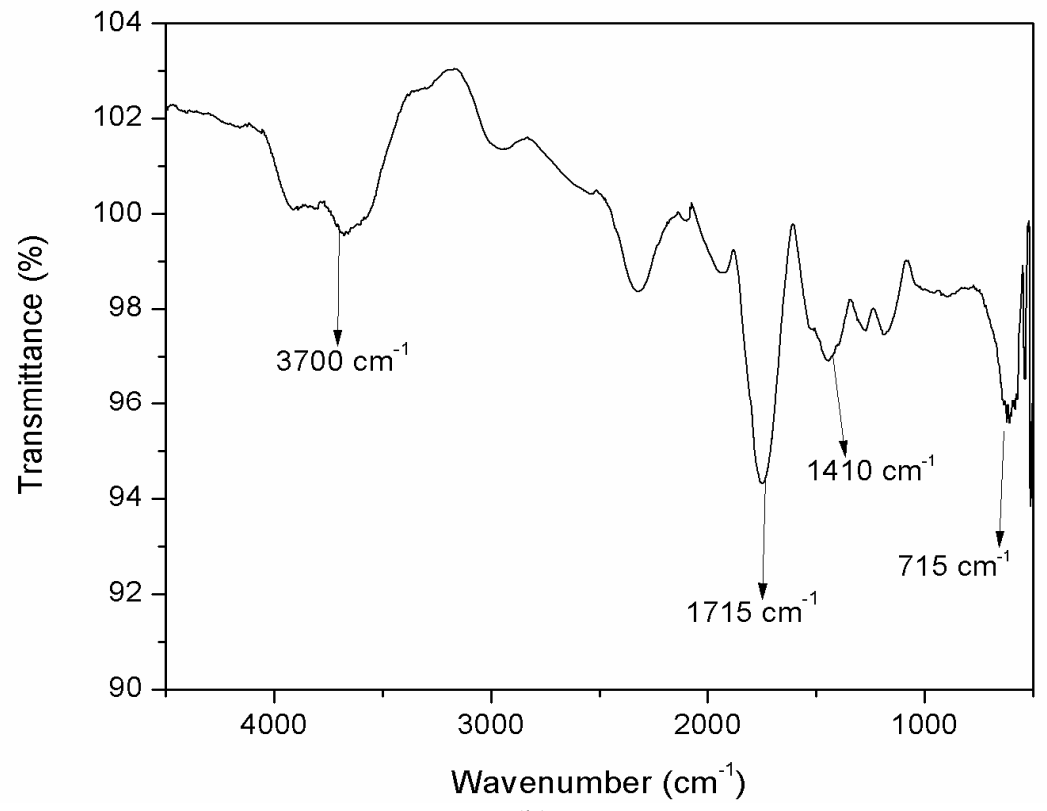

(b)

Fig.-1: IR Spectra of (a) CQAE (b) CQEE

\section{Gas Chromatography-Mass Spectroscopy Analysis (GC- MS)}

GC-MS Chromatogram of Cissus quadrangularis (acid and ethanol extracts) are represented in Fig.-2. The mass spectra of disiloxane, 1, 3-diethoxy-1, 1, 3, 3-tetramethyl and ethyl oleate are shown in Fig.-3. With the help of the NIST library, the structure of the compound existing in the extracts were analyzed. Based on the peak area, predominant 6 compounds were identified for CQAE and 4 compounds for CQEE. The structure of the compounds is represented in Fig.-4.

The compounds are (a) disiloxane,1,3-diethoxy-1,1,3,3-tetramethyl (b) cyclotetrasiloxane, octamethyl- (c) linoleic acid ethyl ester (d) 4-hydroxy chalcone (e) benzo (a) heptalene-7, 9-dione, 5, 6-dihydro-1, 2, 3, 
RASĀYAN J. Chem.

Vol. 12 | No. 3 |1326 - 1339| July - September | 2019

10-tetramethoxy (f) stigmasta-3,5 diene in CQAE. Predominant compounds of CQEE are (a.1) ethyl oleate (b.1) 9-octadecenoicacid pentyl ester (c.1) 7, 11, 15 - trimethyl-3-methylidenehexadec-1-ene (d.1) n- hexadecanoic acid.

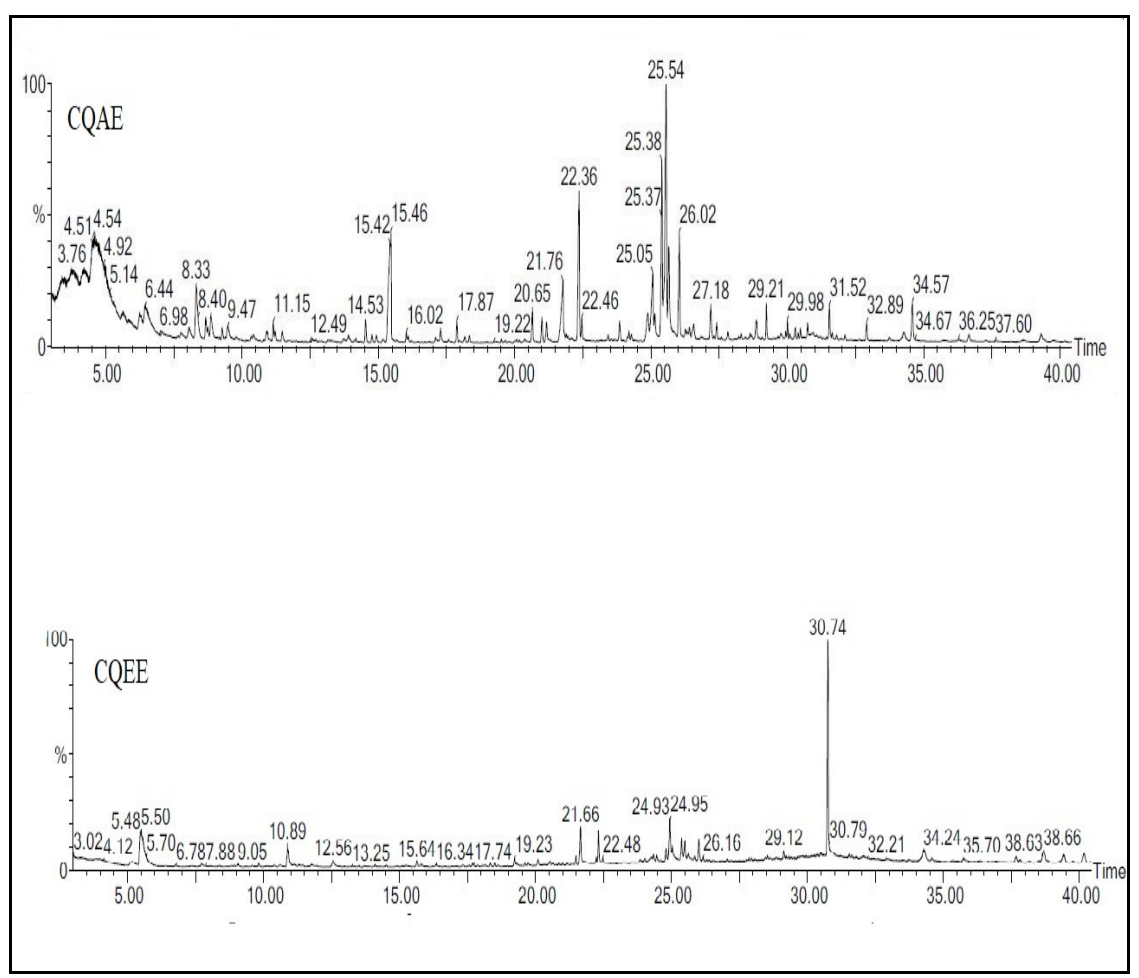

Fig.-2: GC-MS Chromatogram of Cissus quadrangularis (CQAE and CQEE)

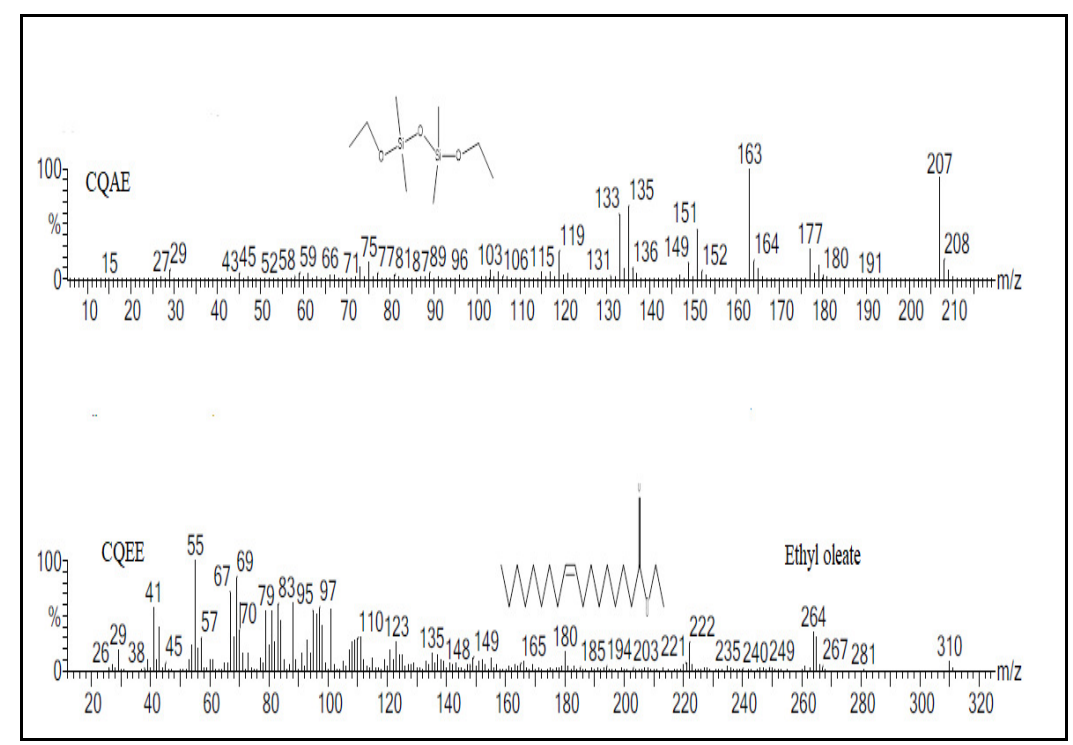

Fig.-3: Mass Spectra of Disiloxane, 1, 3-diethoxy-1, 1, 3, 3-tetramethyl and ethyl oleate

Out of these, in CQAE disiloxane,1, 3-diethoxy-1,1,3,3-tetramethyl relates to the maximum peak area of $6.320 \%$ and the probability of matching is $77.7 \%$, comprising of electronegative atoms such as oxygen. In CQEE, the major component is ethyl oleate of peak area $6.041 \%$ containing oxygen atoms. 


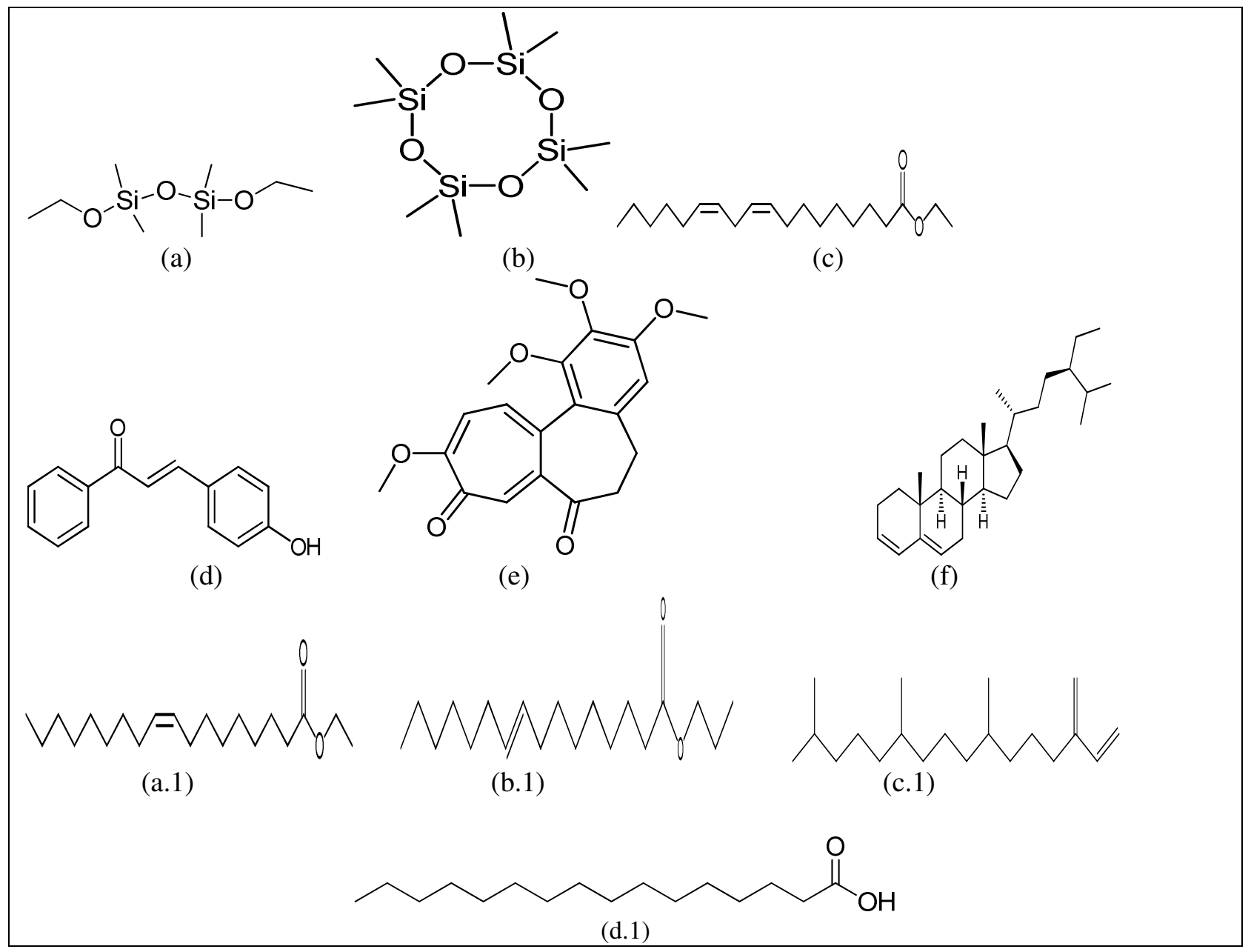

\section{Gravimetric Measurements}

Fig.-4: Structure of Predominant Compounds

The efficiency of the inhibitor at diverse concentrations $(2-12 \mathrm{v} / \mathrm{v} \%)$ on mild steel in $0.5 \mathrm{M}$ sulphuric acid was analyzed and results are accessible in Table-1. It denotes that as the concentration CQAE and CQEE increased the efficiency also increased whereas the corrosion rate reduced.

Table-1: Inhibition Efficiencies at Different Concentrations of CQAE and CQEE on Mild Steel in $0.5 \mathrm{M} \mathrm{H}_{2} \mathrm{SO}_{4}$ attained by Mass Loss Measurements at Room Temperature

\begin{tabular}{c|c|c|c|c}
\hline $\begin{array}{c}\text { Name of the } \\
\text { Inhibitor }\end{array}$ & $\begin{array}{c}\text { Conc. } \\
(\mathrm{v} / \mathrm{v} \%)\end{array}$ & $\begin{array}{c}\text { IE } \\
(\%)\end{array}$ & $\begin{array}{c}\text { Surface } \\
\text { Coverage }(\theta)\end{array}$ & $\begin{array}{c}\text { CR } \\
(\mathrm{mpy})\end{array}$ \\
\hline Blank & - & - & - & 7682.246 \\
\hline \multirow{5}{*}{ CQAE } & 2 & 76.82 & 0.7682 & 1780.85 \\
\cline { 2 - 5 } & 4 & 81.52 & 0.8152 & 1420.00 \\
\cline { 2 - 5 } & 6 & 86.88 & 0.8688 & 1007.94 \\
\cline { 2 - 5 } & 8 & 87.23 & 0.8723 & 981.12 \\
\cline { 2 - 5 } & 10 & 88.29 & 0.8829 & 899.69 \\
\hline \multirow{5}{*}{ CQEE } & 12 & 89.45 & 0.8945 & 810.45 \\
& 14 & 89.48 & 0.8948 & 810.11 \\
\cline { 2 - 5 } & 2 & 47.71 & 0.4771 & 4017.16 \\
\hline & 4 & 50.49 & 0.5049 & 3803.57 \\
\hline
\end{tabular}


RASĀYAN J. Chem.

Vol. 12 | No. 3 |1326 - 1339| July - September | 2019

\begin{tabular}{c|c|c|c|c}
\hline & 8 & 67.16 & 0.6716 & 2523.03 \\
\cline { 2 - 5 } & 10 & 71.05 & 0.7105 & 2224.11 \\
\cline { 2 - 5 } & 12 & 75.54 & 0.7554 & 1879.35 \\
\cline { 2 - 5 } & 14 & 75.59 & 0.7559 & 1855.12 \\
\hline
\end{tabular}

Beyond $12 \mathrm{v} / \mathrm{v} \%$ even though the concentration has increased the efficiency attained a saturation level indicating the optimum concentration. In CQAE, even at a minimum concentration of $2 \mathrm{v} / \mathrm{v} \%$ the efficiency reached to $76.82 \%$ whereas for CQEE at $2 \mathrm{v} / \mathrm{v} \%$ efficiency was $47.71 \%$. Increase of concentration of CQAE and CQEE increased the adsorption of the organic moieties on the metal surface in turn surface coverage increased thus protecting the metal from immediate aggressiveness of acid. Comparing CQAE and CQEE, increased efficacy of CQAE could be due to the existence of more organic compounds comprising hetero atoms and $\pi$-electrons, high molecular weight compounds compared to CQEE thus providing more adsorption sites.

\section{Role of Temperature on IE}

The role of temperature on the corrosion process occurring at the metal surface with and without the influence of the inhibitors (CQAE and CQEE) in 0.5M sulphuric acid were evaluated in the temperature range $313-333 \mathrm{~K}$.

Table-2: Inhibition Efficiencies of CQAE and CQEE Inhibitors on Mild Steel in 0.5M Sulphuric Acid at Higher Temperatures

\begin{tabular}{|c|c|c|c|c|c|c|c|c|c|}
\hline \multirow{3}{*}{ Inhibitor } & \multirow{3}{*}{$\begin{array}{c}\text { Conc. } \\
(\mathrm{v} / \mathrm{v} \\
\%)\end{array}$} & \multicolumn{8}{|c|}{ Temperature } \\
\hline & & \multicolumn{2}{|c|}{303} & \multicolumn{2}{|c|}{313} & \multicolumn{2}{|c|}{323} & \multicolumn{2}{|c|}{333} \\
\hline & & IE\% & CR(mpy) & IE\% & CR(mpy) & IE\% & $\mathrm{CR}$ (mpy) & IE\% & $\mathrm{CR}$ (mpy) \\
\hline Blank & - & - & 7705.17 & - & 10666.10 & - & 16822.04 & - & 29997.04 \\
\hline \multirow[b]{3}{*}{ CQAE } & 2 & 75.8 & 588.21 & 60.10 & 4125.22 & 42.98 & 9548.22 & 35.65 & 18999.22 \\
\hline & 6 & 84.89 & 380.96 & 74.34 & 2588.42 & 63.87 & 5734.67 & 55.67 & 12876.87 \\
\hline & 12 & 89.08 & 245.12 & 75.67 & 2521.34 & 77.04 & 2410.77 & 64.5 & 10674.87 \\
\hline \multirow[b]{3}{*}{ CQEE } & 2 & 47.86 & 4017.16 & 45.06 & 5860.43 & 43.13 & 9567.45 & 39.90 & 18028.95 \\
\hline & 6 & 68.33 & 3377.87 & 59.13 & 4359.48 & 55.47 & 7490.12 & 43.72 & 16882.02 \\
\hline & 12 & 75.34 & 1900.03 & 61.21 & 4137.12 & 59.32 & 6843.51 & 53.66 & 13900.60 \\
\hline
\end{tabular}

It can be noticed from Table- 2 that as the temperature is inflated there is a rise in corrosion rate resulting in desorption of the molecules exposing more surface area to corrosion ${ }^{18}$. Influence of temperature on inhibitor ability was interrelated by Arrhenius and Transition state equation. In Fig.-5 a linear graph was obtained for Arrhenius and Transition plots. $E_{a}$ values were calculated from the slope and it is tabulated in Table-3. Datas for $\Delta \mathrm{H}^{\circ}$ and $\Delta \mathrm{S}^{\circ}$ were evaluated from the linear plot of the slope. It is apparent from Table3 that $\mathrm{E}_{\mathrm{a}}$ values of the inhibitors $\left(70.97\right.$ and $\left.54.32 \mathrm{~kJ} \mathrm{~mol}^{-1}\right)$ are higher than blank $\left(37.87 \mathrm{~kJ} \mathrm{~mol}^{-1}\right)$ which intimates that in presence of inhibitors a protective barrier is formed thus impeding corrosion. Positive $\Delta \mathrm{H}^{\mathrm{o}}\left(69.33\right.$ and $\left.51.31 \mathrm{~kJ} \mathrm{~mol}^{-1}\right)$ suggests endothermic nature intimates that in presence of inhibitor the dissolution of metal is retarded ${ }^{19}$. Negative values of $\Delta \mathrm{S}^{\mathrm{o}}\left(-18.25,-11.12 \mathrm{~J} \mathrm{~mol}^{-1} \mathrm{~K}^{-1}\right)$ specifies a decrease in disorderness occurs from reactant to activated complex ${ }^{20,21}$.

Table-3: Activation Parameters of Dissolution of Metal in the Corrosive Medium in the Non-existence and Presence of Inhibitors

\begin{tabular}{|c|c|c|c|c|c|c|c|}
\hline \multirow{2}{*}{ Inhibitor } & \multirow{2}{*}{$\begin{array}{c}\mathrm{E}_{\mathrm{a}} \\
\mathrm{kJ} \mathrm{mol}^{-1}\end{array}$} & \multirow{2}{*}{$\begin{array}{c}\Delta \mathrm{H}^{\mathrm{o}} \\
\mathrm{kJ} \mathrm{mol}^{-1}\end{array}$} & \multirow{2}{*}{$\begin{array}{c}\Delta \mathrm{S}^{\mathrm{o}} \\
\mathrm{J} \mathrm{mol}^{-1} \mathrm{~K}^{-1}\end{array}$} & \multicolumn{4}{|c|}{$\begin{array}{c}+\Delta \mathrm{G}^{\mathrm{o}} \\
\left(\mathrm{kJ} \mathrm{mol}^{-1}\right)\end{array}$} \\
\hline & & & & 303 & 313 & 323 & 333 \\
\hline Blank & 37.87 & 35.24 & -46.52 & 12.31 & 13.37 & 14.4 & 15.5 \\
\hline CQAE & 70.97 & 69.33 & -18.25 & 5.66 & 5.97 & 6.35 & 6.80 \\
\hline CQEE & 54.32 & 51.31 & -11.12 & 4.51 & 4.75 & 5.38 & 5.66 \\
\hline
\end{tabular}


RASĀYAN J. Chem.

Vol. 12 | No. 3 |1326 - 1339| July - September | 2019

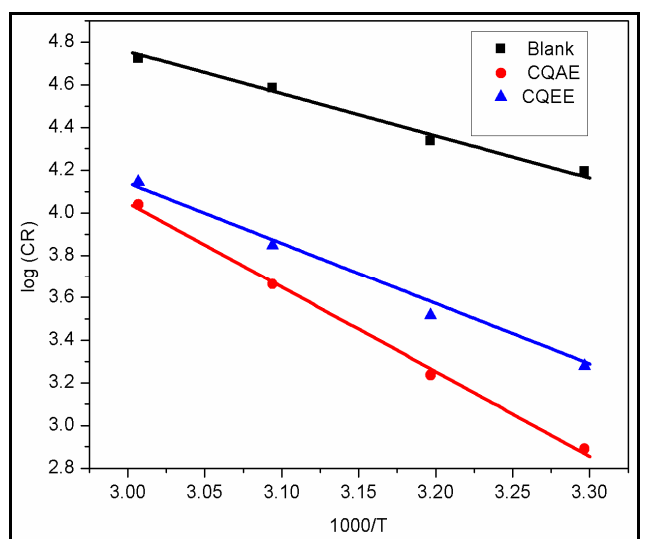

(a)

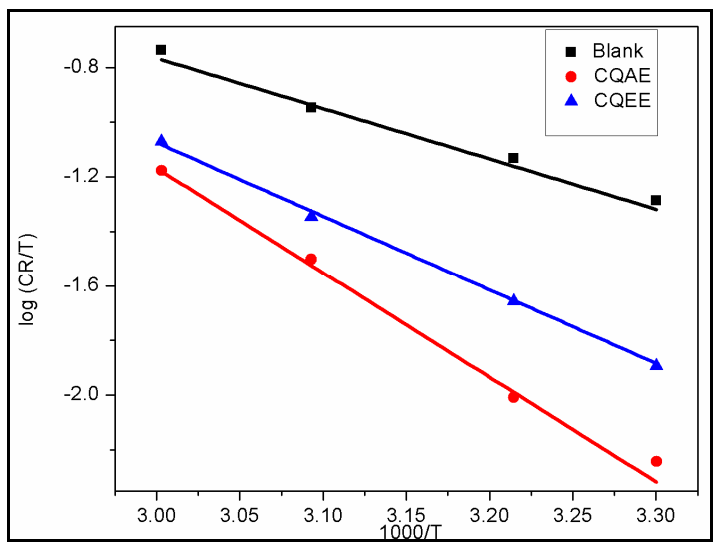

(b)

Fig.-5: (a) Arrhenius Plot (b) Transition Plots of CQAE and CQEE

Positive $\Delta \mathrm{G}^{\mathrm{o}}$ values stipulate the instability of the activated complex. A straight line plot is attained for $\ln K_{\text {ads }}$ vs $1 / \mathrm{T}$ having a slope $\left(\Delta \mathrm{H}_{\text {ads }}^{\mathrm{o}} / \mathrm{R}\right)$ and intercept $\left[\left(\Delta \mathrm{S}_{\text {ads }}^{\mathrm{o}} / \mathrm{R}\right)+\ln (1 / 55.5)\right]$ and it is represented in Fig.-6.

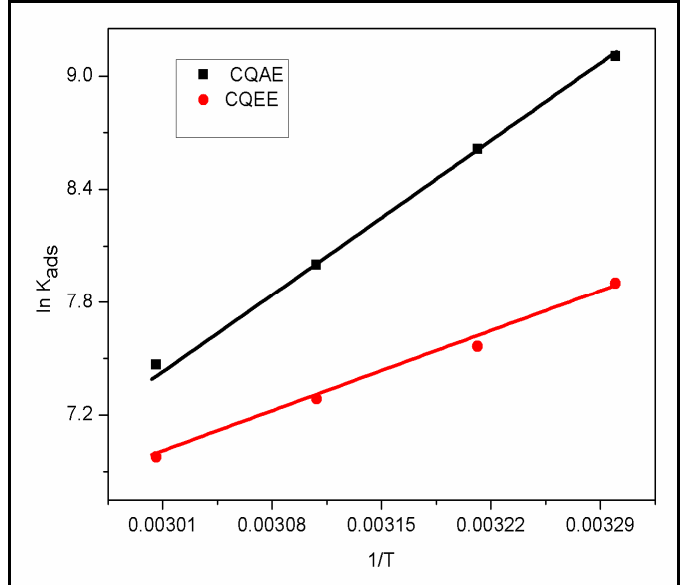

(a)

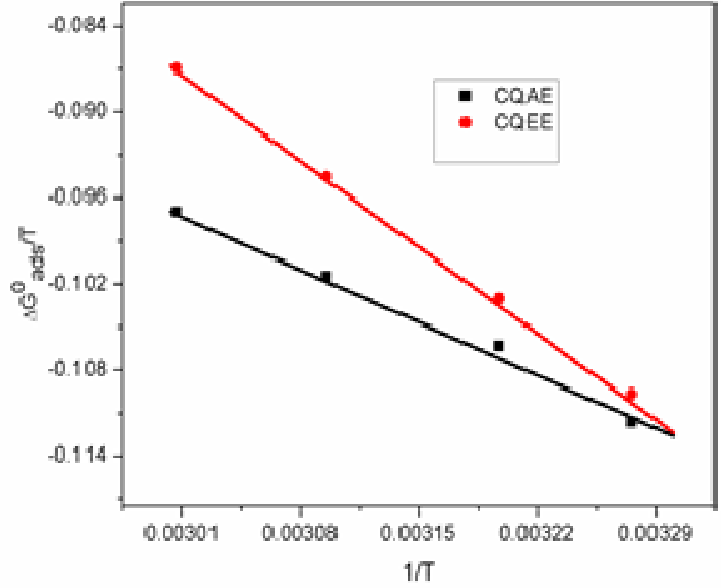

(b)

Fig.-6: (a) Van't Hoff (b) Gibbs-Helmholtz Plots for Mild Steel in 0.5 $\mathrm{M} \mathrm{H}_{2} \mathrm{SO}_{4}$ in presence of Acid and Ethanol Extracts of CQ

From Table-4 it is evident that $\Delta \mathrm{H}^{\mathrm{o}}$ is negative $\left(-25.29,-22.68 \mathrm{~kJ} \mathrm{~mol}^{-1}\right)$ indicates exothermic adsorption process. The value of $\Delta \mathrm{G}^{\mathrm{o}}$ for CQAE and CQEE are around -27.89 to $-32.77 \mathrm{~kJ} \mathrm{~mol}^{-1}$ suggesting a mixed mode of adsorption predominantly physisorption.

\section{Adsorption isotherm}

The corrosion inhibition behavior on the metal surface is highly based on adsorption process ${ }^{22}$. The mass loss measurements provides $\theta$ values with varying concentrations of CQAE and CQEE. The experimental data were fitted for various adsorption isotherms like Frumkin, Freundlich, Langmuir, Flory-Huggins and Temkin isotherms. The relation between inhibitor concentration $\left(\mathrm{C}_{\mathrm{in}}\right)$ and surface coverage $(\theta)$ is given by the equation,

$$
\frac{\mathrm{C}_{\text {in }}}{\theta}=\frac{1}{\mathrm{~K}_{\text {ads }}}+\mathrm{C}_{\text {in }}
$$


RASĀYAN J. Chem.

Vol. 12 | No. 3 |1326 - 1339| July - September | 2019

Table-4: Van't Hoff Equation and Gibbs Helmholtz Equation Derived from Thermodynamic Parameters

\begin{tabular}{c|c|c|c|c|c|c|c}
\hline \multirow{2}{*}{ Inhibitor } & \multicolumn{2}{|c|}{ Van't Hoff equation } & $\begin{array}{c}\text { Gibbs- } \\
\text { Helmholtz } \\
\text { equation }\end{array}$ & \multicolumn{4}{|c}{$\begin{array}{c}\Delta \mathrm{G}_{\mathrm{ads}}^{\circ} \\
\mathrm{kJ} \mathrm{mol}^{-1}\end{array}$} \\
\cline { 2 - 8 } & $\begin{array}{c}\Delta \mathrm{H}_{\mathrm{ads}}^{\circ} \\
\mathrm{kJ} \mathrm{mol}^{-1}\end{array}$ & $\begin{array}{c}\Delta \mathrm{S}_{\mathrm{ads}}^{\circ} \\
\mathrm{kJ} \mathrm{mol}^{-1}\end{array}$ & $\begin{array}{c}\Delta \mathrm{H}_{\mathrm{ads}}^{\circ} \\
\mathrm{kJ} \mathrm{mol}^{-1}\end{array}$ & $303 \mathrm{~K}$ & $313 \mathrm{~K}$ & $323 \mathrm{~K}$ & $333 \mathrm{~K}$ \\
\hline CQAE & -25.29 & -0.095 & -25.29 & -32.77 & -32.46 & -29.35 & -28.93 \\
\hline CQEE & -22.68 & -0.092 & -22.68 & -30.33 & -28.67 & -28.47 & -27.89 \\
\hline
\end{tabular}

Linear plots were attained for $\mathrm{C} / \theta$ vs $\mathrm{C}$ and it is shown in Fig.-7. Langmuir adsorption isotherm fitted well.

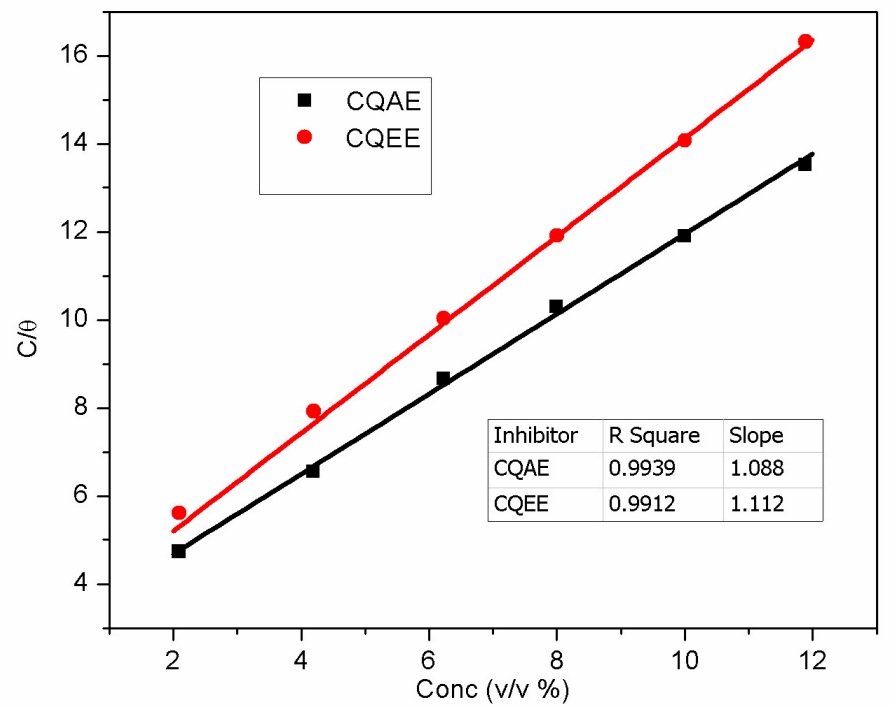

Fig.-7: Langmuir Adsorption Isotherm Plot of Acid and Ethanol Extracts of C.quadrangularis on Mild Steel

Moreover, $\mathrm{K}_{\mathrm{ads}}$ value is acquired from the intercept of the graph and it is tabulated in Table- 5 and $\Delta \mathrm{G}_{\text {ads }}^{\mathrm{o}}$ can be calculated by using the equation,

$$
\Delta \mathrm{G}_{\text {ads }}^{\mathrm{O}}=-\mathrm{RT} \ln (55.5 \mathrm{~K})
$$

Since, $\Delta \mathrm{G}_{\text {ads }}^{\mathrm{o}}$ value is negative which specifies spontaneous adsorption of CQAE and CQEE on the metal surface via physisorption mechanism ${ }^{23}$. The calculated values of $\Delta \mathrm{G}^{\mathrm{o}}\left(-30.17,-30.26 \mathrm{~kJ} \mathrm{~mol}^{-1}\right)$ implies mixed-mode predominantly physisorption.

Table-5: Langmuir Adsorption Parameters for CQAE and CQEE

\begin{tabular}{c|c|c|c|c}
\hline Inhibitor & $\mathrm{R}^{2}$ & Slope & $\mathrm{K}\left(\mathrm{mol} \mathrm{lt}^{-1}\right)$ & $-\Delta \mathrm{G}_{\mathrm{ads}}^{\circ}\left(\mathrm{kJ} \mathrm{mol}^{-1}\right)$ \\
\hline CQAE & 0.9939 & 1.08 & 296.6 & 30.17 \\
\hline CQEE & 0.9912 & 1.11 & 286.6 & 30.26 \\
\hline
\end{tabular}

\section{Electrochemical Impedance Spectroscopy}

Impedance spectroscopy helps to understand the kinetics and surface characteristics of the metal. The nyquist plot is the representation of reaction occurring at the surface ${ }^{24}$. Fig. -8 demonstrates Nyquist plots of selected concentrations of CQAE and CQEE. On analyzing Table- 6 the $\mathrm{R}_{\mathrm{ct}}$ value increases as the concentration of the inhibitors (CQAE and CQEE) increases proving the presence of a protective layer on 
the metal surface. Reduction in $\mathrm{C}_{\mathrm{dl}}$ with the rise in inhibitor concentration is observed owing to increase in adsorption, which contributes more surface coverage, in turn, enhancing the inhibition efficiency ${ }^{25}$. This attributed to the progress in the thickness of the double layer due to the presence of adsorbed molecules of the extracts thus impeding mild steel corrosion /electrolyte interface. Variation in $\mathrm{C}_{\mathrm{dl}}$ values indicates that water molecules are altered by CQAE and CQEE.

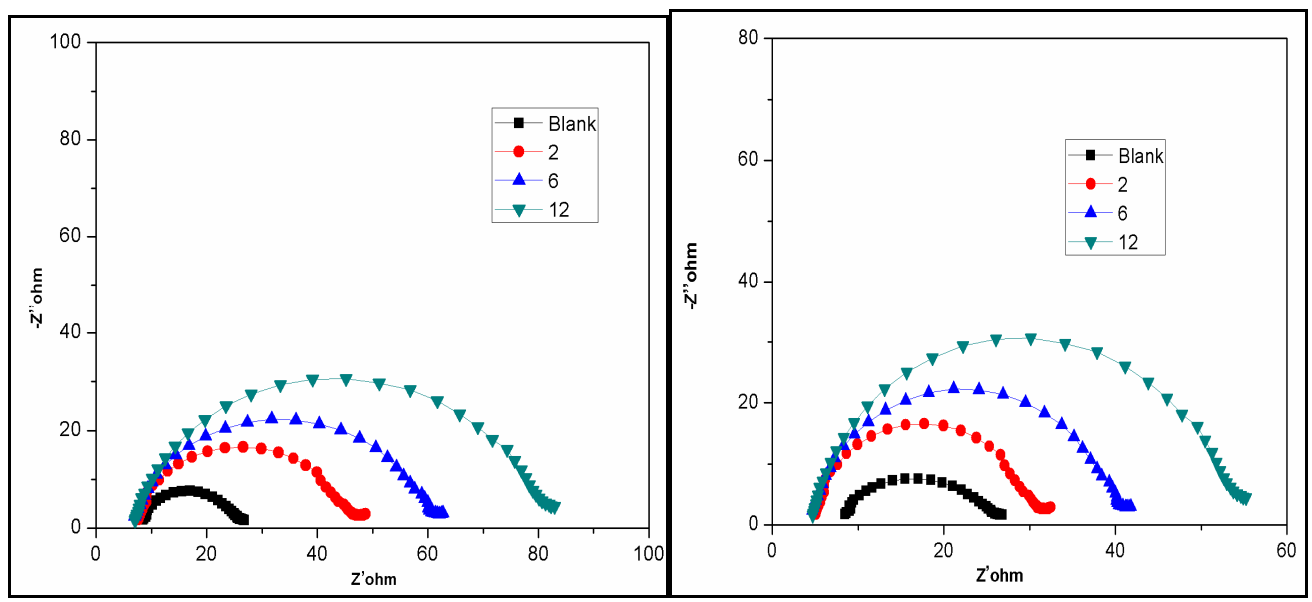

(a)

(b)

Fig.-8: Nyquist Plots of (a) CQAE (b) CQEE

Table-6: AC-Impedance Parameters for Mild Steel Corrosion in $0.5 \mathrm{M} \mathrm{H}_{2} \mathrm{SO}_{4}$ in the Absence and Presence of Selected Concentrations of Acid and Ethanol Extracts of C.quadrangularis

\begin{tabular}{c|c|c|c|c}
\hline $\begin{array}{c}\text { Name of the } \\
\text { inhibitor }\end{array}$ & $\begin{array}{c}\text { Conc. } \\
(\mathrm{v} / \mathrm{v} \%)\end{array}$ & $\begin{array}{c}\mathrm{R}_{\mathrm{ct}} \\
(\mathrm{ohm} \mathrm{cm})^{2}\end{array}$ & $\begin{array}{c}\mathrm{C}_{\mathrm{dl}} \\
\left(\mu \mathrm{F} / \mathrm{cm}^{2}\right)\end{array}$ & IE (\%) \\
\hline Blank & - & 17 & 61 & - \\
& 2 & 42 & 56.5 & 59.5 \\
& 6 & 57 & 40.1 & 70 \\
CQAE & 12 & 77 & 37.9 & 78 \\
\hline & 2 & 25 & 42.3 & 32 \\
CQEE & 6 & 40 & 35.1 & 67.5 \\
\hline
\end{tabular}
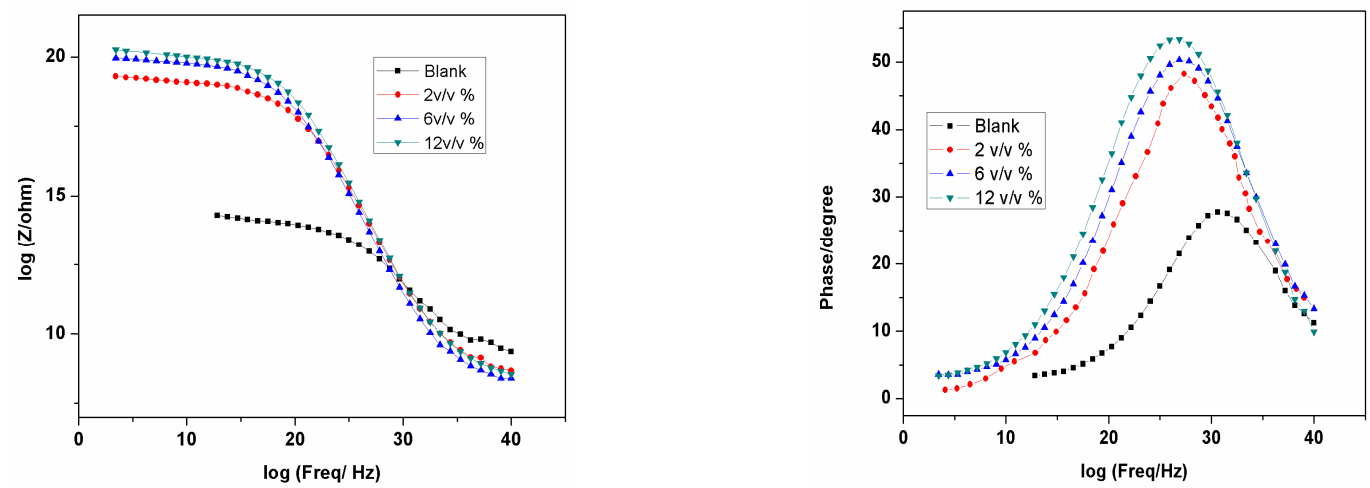

(a) 
RASĀYAN J. Chem.

Vol. 12 | No. 3 |1326 - 1339| July - September | 2019
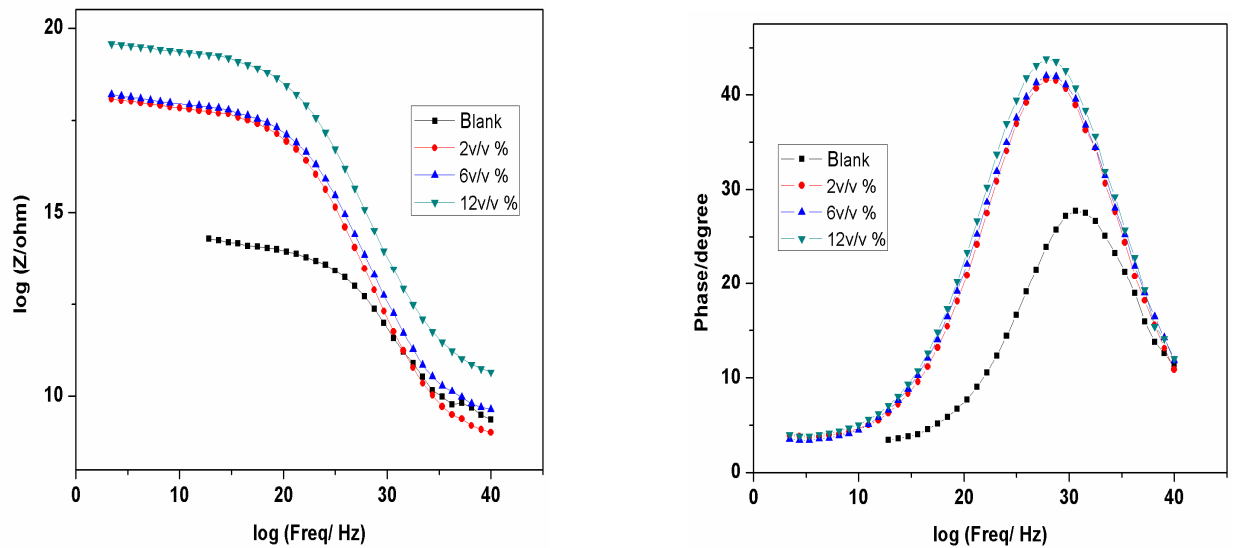

(b)

Fig.-9: Bode Plots of (a) CQAE (b) CQEE

Bode plots of corrosion on metal in non-existence and presence of inhibitors of concentrations $(2,6$ and $12 \mathrm{v} / \mathrm{v} \%$ ) in $0.5 \mathrm{M} \mathrm{H}_{2} \mathrm{SO}_{4}$ are illustrated in Fig.-9. It is inferred from the plot that as the concentration of CQAE and CQEE increases phase angle increases which specifies the reduction in surface inhomogeneity. Also, a resistance towards corrosion rises as the concentration rises suggested reduced metal dissolution ${ }^{26}$.

\section{Potentiodynamic Polarisation Techniques}

Emblematic Tafel plots for mild steel in $0.5 \mathrm{M} \mathrm{H}_{2} \mathrm{SO}_{4}$ of varying concentrations are depicted in Fig.-10. It is apparent from the Fig.-10 that as the concentration of CQAE and CQEE increases the corrosion potential $\left(\mathrm{E}_{\text {corr }}\right)$ slightly shifted proposing mixed behavior of the inhibitor with slightly cathodic.

As per literature, $E_{\text {corr }}$ value less than $85 \mathrm{mV}$ indicates the mixed nature of the inhibitor with reference to that the maximum displacement in our current research was $70 \mathrm{mV}$ proving the mixed behavior ${ }^{27,28}$. The parameters such as $b_{a}, b_{c}, I_{c o r r}, E_{\text {corr }}$ and inhibition efficiency are in Table-7. It can be grasped from Table-7, that $\mathrm{I}_{\text {corr }}$ value decreases as the concentration of $C$. quadrangularis increases evidencing the adsorption process takes place thus impeding corrosion.

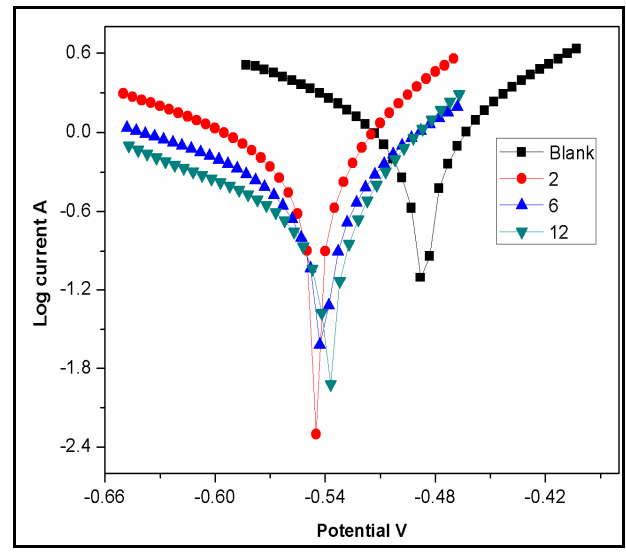

(a)

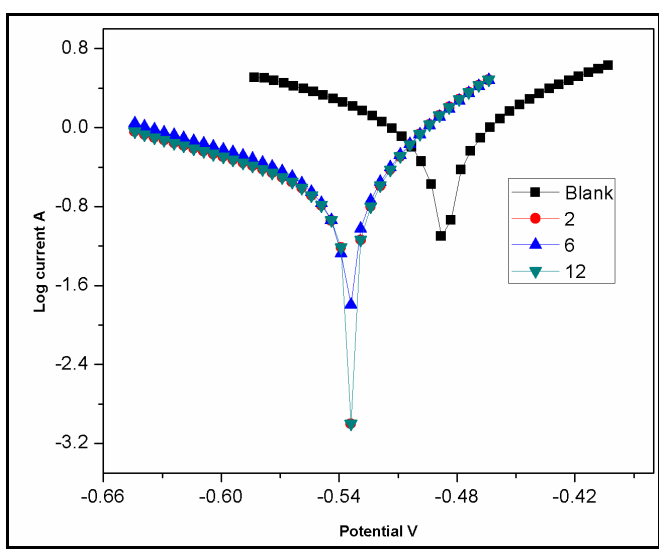

(b)

Fig.-10: Tafel Curves for Mild Steel in 0.5 $\mathrm{M} \mathrm{H}_{2} \mathrm{SO}_{4}$ Solution in the Absence and Presence of Selected Concentrations of (a) CQAE (b) CQEE

Scanning Electron Microscope (SEM)

On analyzing SEM visuals of blank, CQAE and CQEE at an optimum concentration of $12 \mathrm{v} / \mathrm{v} \%$ in Fig.-11 the morphology of the metal surface can be visualized. Fig.-11a (blank) indicates cracks, pits and 
RASĀYAN J. Chem.

Vol. 12 | No. 3 |1326 - 1339| July - September | 2019

rough surface owing to the violent attack of acid. The presence of inhibitors (CQAE and CQEE) in Fig.$11 \mathrm{~b}$ and $\mathrm{c}$ represents the formation of the protective layer thus reducing corrosion, with respect to vibrant interaction of the inhibitor molecules on the metal surface

Table -7: Corrosion Parameters for Metal in $0.5 \mathrm{M} \mathrm{H}_{2} \mathrm{SO}_{4}$ of Acid and Ethanol Extracts of C.quadrangularis by Potentiodynamic Polarization Method

\begin{tabular}{c|c|c|c|c|c|c}
\hline \multirow{2}{*}{ Inhibitor } & \multirow{2}{*}{$\begin{array}{c}\text { Conc. } \\
(\mathrm{v} / \mathrm{v} \%)\end{array}$} & \multicolumn{2}{|c|}{$\begin{array}{c}\text { Tafel Slopes } \\
(\mathrm{mV} / \mathrm{dec})\end{array}$} & \multirow{2}{*}{$\begin{array}{c}-\mathrm{E}_{\text {corr }} \\
(\mathrm{mV})\end{array}$} & \multirow{2}{*}{$\begin{array}{c}\mathrm{I}_{\text {corr }} \\
\left(\mu \mathrm{A} / \mathrm{cm}^{2}\right)\end{array}$} & IE $(\%)$ \\
\cline { 3 - 4 } & & $\mathrm{b}_{\mathrm{a}}$ & $\mathrm{b}_{\mathrm{c}}$ & & 520 & - \\
\hline \multirow{2}{*}{ Blank } & - & 62 & 91 & 490 & 520 & 58.6 \\
& 2 & 80 & 175 & 538 & 215 & 70.1 \\
& 6 & 71 & 170 & 537 & 155 & 78.2 \\
\hline & 12 & 59 & 161 & 536 & 113 & 34.6 \\
CQAE & 2 & 70 & 168 & 545 & 340 & 58.3 \\
& 6 & 61 & 152 & 540 & 216 & 65.4 \\
\hline
\end{tabular}

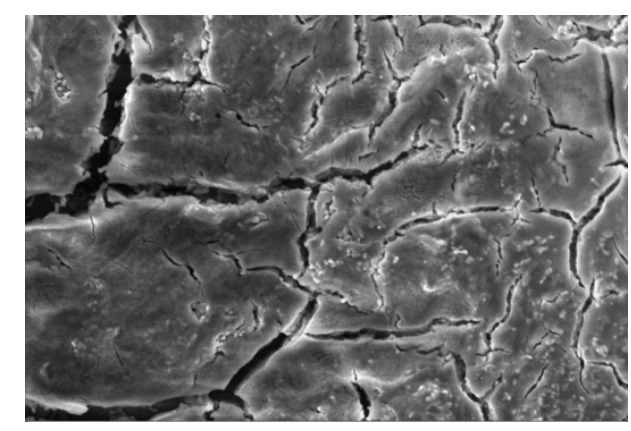

(a)

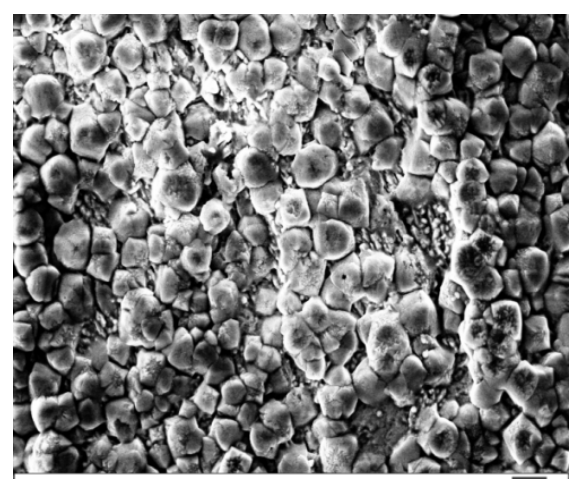

(b)

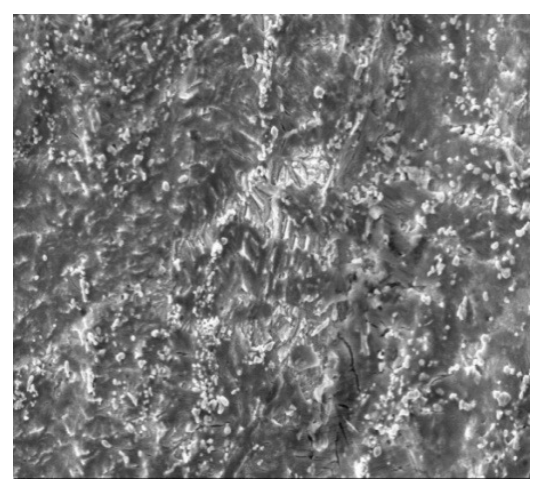

(c)

Fig.-11: SEM Visuals of (a) Blank (b) CQAE (c) CQEE

\section{Atomic Force Microscopy}

AFM is a new technique to analyze the characteristics of the defensive layer on the metal surface ${ }^{29}$. A 3D and 2D AFM images of metal specimens in $0.5 \mathrm{M} \mathrm{H}_{2} \mathrm{SO}_{4}$ are represented in Fig.-12. AFM visuals of metal in the presence of inhibitors (CQAE and CQEE) at an optimum concentration (12v/v \%) are portrayed in Fig.-12 b and c. It can be viewed from the images that a blank specimen image displays more roughness in comparison with CQAE and CQEE images. Average roughness is calculated for the specimen in acid solution and it is found to be $180.17 \mathrm{~nm}$ whereas for CQAE and CQEE are $95.62 \mathrm{~nm}$ and $106.12 \mathrm{~nm}$ respectively. The reduction in average roughness validates the formation of the protective layer due to CQAE and $\mathrm{CQEE}^{30}$. 

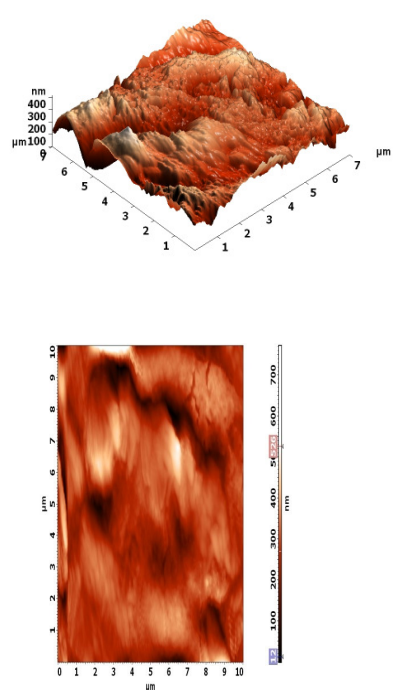

(a)
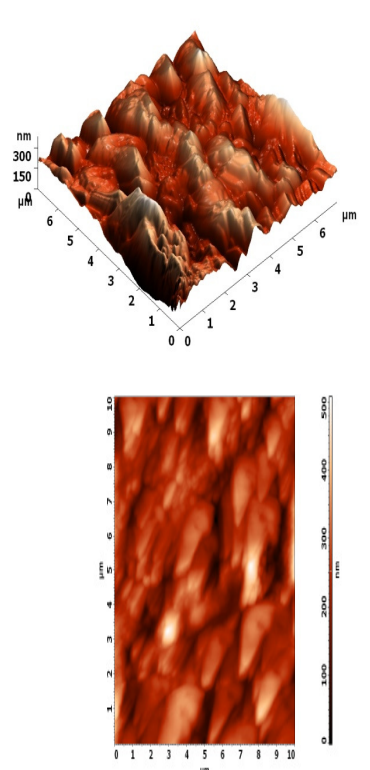

(b)
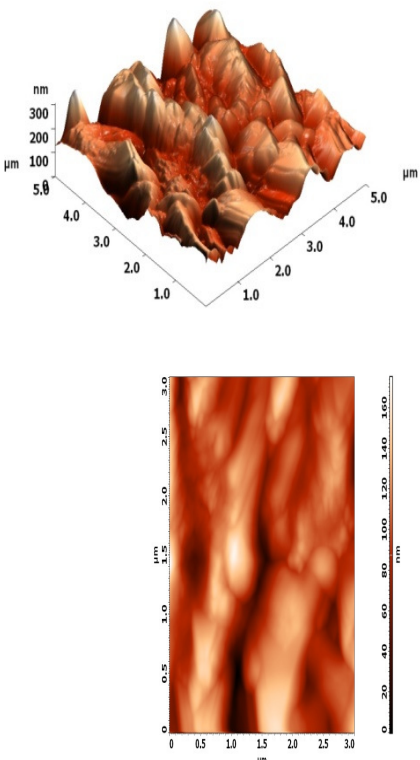

(c)

Fig.-12: AFM 3D and 2D Images of (a) Blank (b) CQAE (c) CQEE

\section{Proposed Mechanism of Inhibition}

In acidic medium, mild steel surface acquires negatively charge owing to the influence of adsorbed $\mathrm{SO}_{4}{ }^{2-}$ ions on the mild steel surface ${ }^{31}$.

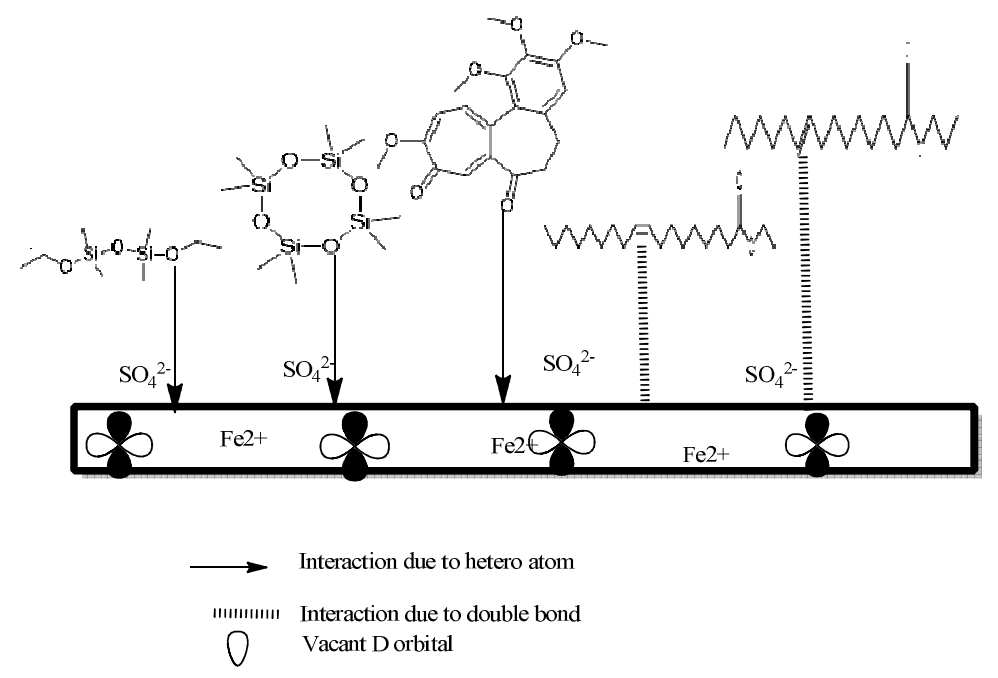

Fig.-13: Schematic Representation for the Proposed Mechanism of Inhibition

In a sulphuric acid medium, the oxygen atoms present in the major predominant compounds such as disiloxane, 1, 3-diethoxy-1, 1, 3, 3-tetramethyl, ethyl oleate gets protonated because of their high electron density hence the inhibitor acquires a positive charge. Due to the electrostatic attraction between negatively charged mild steel surface and inhibitor with positive charge interacts and adsorption takes place. The protonated inhibitor easily adsorbed on cathodic site of the metal thus decreasing the evolution of hydrogen $^{32}$. This adsorption outcome resulted in the development of the protective layer at the mild 


\section{RASĀYAN J. Chem.}

Vol. 12 | No. 3 |1326 - 1339| July - September | 2019

steel/electrolyte interface. A coordinate bond exists between the lone pairs of electrons in inhibitor molecules and vacant d-orbitals of metal surface ${ }^{33}$. CQAE possess enhanced inhibition efficiency due to the existence of delocalized $\pi$-electrons, leading to effective adsorption of the metal and also due to the high molecular weight compound in CQAE.

\section{CONCLUSION}

- At an optimum concentration of $12 \mathrm{v} / \mathrm{v} \%$ the maximum efficiency attained for CQAE and CQEE are $89.45 \%$ and $75.54 \%$.

- IR and GC-MS analysis confirm the presence of active species in the inhibitors.

- Electrochemical techniques affirm the inhibiting behavior of the inhibitor.

- Tafel curves suggest the mixed nature of CQAE and CQEE inhibitors.

- SEM and AFM studies provide evidence for the formation of the protective layer.

- Finally, to conclude, CQAE possess enhanced inhibition efficiency than CQEE due to the existence of active high molecular weight predominant compounds.

\section{REFERENCES}

1. P. M. Dasami, K. Parameswari and S. Chitra, Measurement, 69, 195(2015), DOI: $10.1016 /$ j.measurement.2015.03.025

2. M. S. Al-Otaibi, A. M. Al-Mayouf, M. Khan, A. A. Mousa and S. A. Al-Mazroa, Arabian Journal of Chemistry, 7 (3), 340(2014), DOI:10.1016/j.arabjc.2012.01.015

3. M. Jokar, T. Shahrabi Farahani and B. Ramezanzadeh, Journal of Taiwan Institute of Chemical Engineers, 63, 436 (2016), DOI:10.1016/j.jtice.2016.02.027

4. M. Gopiraman, P. Sakunthala, R. Kanmani, V. Alex Ramani and N. Sulochana, Ionics, 17(9), 843(2011), DOI:10.1007/s11581-011-0584-9.

5. O. A. Abdullatef, Egyptian Journal of Petroleum, 24(4), 505(2015), DOI: 10.1016/j.ejpe.2015.03.003.

6. S. Jyothi, Y.V. Subba Rao and P.S. Samuel Ratnakumar, Rasayan Journal of Chemistry, 12(2), 537 (2019), DOI:10.31788/RJC.2019 .122 5000

7. M. A. Deyab, M.M. Osman, A.E. Elkholyand and F.El-Taib Heakal, RSC Advances, 7, 45241(2017), DOI: $10.1039 / \mathrm{c} 7 \mathrm{ra07979f.}$

8. K. K. Anupama, K. Ramya and A. Joseph, Journal of Molecular Liquids, 216, 146(2016), DOI:10.1016/j.molliq.2016.01.019.

9. A.S. Fouda, A. Emam, R. Refat and M. Nageeb, Journal of Analytical \& Pharmaceutical Research, 6(1), 1(2017), DOI:10.15406/japlr.2017.06.00168.

10. I.Y. Suleiman, S.A. Salihu and O.S. Emokpaire, O.C. Ogheneme and L. Shuaibu, Portugaliae Electrochimica Acta, 35 (3),143(2017), DOI: 10.4152/pea.201703143.

11. N. Raghavendran and J. Ishwara Bhat, Journal of BioTribo Corrosion, 4(1),1(2018), DOI: 10.1007/S40735-017-0112-1.

12. S. Geetu, M. Rakesh, R. Preeti, Natural Product Research, 21,522(2007), DOI: 10.1080/14786410601130471

13. D. Jalajaa, S. Jyothi, V.R. Muruganantham and J. Mallika, Rasayan Journal of Chemistry, 12(2) ,545 (2019), DOI:10. 31788/RJC .2019.12 24096.

14. T. A. Salman and A. B. Mohammed, Rasayan Journal of Chemistry, 10(3),815(2017), DOI: 10.7324/RJC.2017.1031751

15. P. Sounthari, A. Kiruthika, J. Saranya, K. Parameswari and S. Chitra, Ecotoxicology and Environmental Safety, 134, 319(2016), DOI:10.1016/j.ecoenv.2015.08.014 .

16. P. Muthukrishnan, P. Prakash, B. Jeyaprabha and K. Shankar, Arabian Journal of Chemistry, (2015) DOI:10.1016/j.arabjc.2015.09.005.

17. V. Swarnalatha and P. Pazhanisamy, Rasayan Journal of Chemistry,11(3),929(2018), DOI: 10.31788/RJC.2018.1132073

18. P. Arockiasamy, X. QueenRosarySheela, G. Thenmozhi, M. Franco, J. Wilson Sahayaraj and R.Jayasanthi, International Journal of Corrosion, 2014, 1, (2014), DOI: 10.1155/2014/679192. 
19. G. Nirmaladevi, J. Saranya, A. Kiruthika, L. O. Olasunkanmi, E. E. Ebenso and S. Chitra, Journal of Molecular Liquids, 232, 9(2017), DOI:10.1016/j.molliq. 2017.02.054.

20. D. M. Gurudatt and N. Mohana, Industrial and Engineering Chemistry Research,53(6), 2092 (2014), DOI: $10.1021 / \mathrm{ie} 402042 \mathrm{~d}$.

21. X. Li, S. Deng, F.M. Hui and G. Mu, Corrosion Science, 51(3), 620(2009), DOI: 10.1016/j.corsci.2008.12.021.

22. Y. Liu, Colloids and Surfaces A, 274, 34(2006), DOI: 10.1016 /j.colsurfa.2005.08.029.

23. E.E. Oguzie, Y. Lia and F.H. Wang, Electrochimica Acta, 53(2), 909(2007), DOI:10.1016/j.electacta.2007.07.076.

24. S. Agiladevi and S. Rajendran, Rasayan Journal of Chemistry, 12(1), 22(2019), DOI: 10.31788/RJC.2019.1215037.

25. T. Deepa and C. Thangavelu, Rasayan Journal of Chemistry, 10(2), 584 (2017), DOI: 10.7324/RJC.2017.1021550.

26. S. Jyothi, K. Rathidevi, D. Jalajaa and P.S. Samuel Ratnakumar, Rasayan Journal of Chemistry, 12(1), 272 (2019), DOI:10.31788/RJC.2019.1214097

27. N. Anusuya, J. Saranya, P. Sounthari, A. Zarrouk and S. Chitra, Journal of Molecular Liquids, 225, 406 (2017), DOI: 10.1016/j.molliq.2016.11. 015.

28. S. Jyothi and K. Rathidevi, Rasayan Journal of Chemistry, 10(4), 1253(2017), DOI: 10.7324/RJC.2017.1041924.

29. P. Muthukrishnan, B. Jeyaprabha and P.Prakash, Arabian Journal of Chemistry, 10, S2343 (2017), DOI:10.1016/j.arabjc.2013.08.011.

30. M. Prabakaran, S.H. Kim, Y. Takoh, V. Raj and I. M. Chung, Journal of Industrial and Engineering Chemistry, 45, 380 (2017), DOI: 10.1016 /j.jiec.2016.10.006.

31. X. Li, S. Deng and H. Fu, Corrosion Science, 62, 163(2012), DOI:10.1016/j.corsci.2012.05.008

32. P.M. Krishnegowda, V.T. Venkatesha, P.M. Krishnegowda and S.B.Shivayogiraju, Industrial \& Engineering Chemistry Research, 52(2),722(2013), DOI:10.1021/ie3018862.

33. A. Lecante, F. Robert, P.A. Blandinieres and C. Roos, Current Applied Physics, 11(3), 714 (2011) DOI:10.1016/j.cap.2010.11.038.

[RJC-5195/2019] 